\title{
WHITE MULBERRY (MORUS ALBA L.) FRUIT-ASSOCIATED BACTERIAL AND FUNGAL MICROBIOTA
}

\author{
Juliana LUKŠA, Elena SERVIENE்* \\ Department of Chemistry and Bioengineering, Vilnius Gediminas Technical University, \\ Sauletekio al. 11, LT-10223 Vilnius, Lithuania
}

Received 06 April 2020; accepted 28 September 2020

\begin{abstract}
Highlights
Next Generation Sequencing approach reveals Morus alba fruit microbial community.

- White mulberry fruits possess high bacterial and fungal microorganism diversity.

Potentially beneficial and pathogenic microorganisms are distributed on M. alba.

Microbiota structure are important for mulberry development and quality of the berries.
\end{abstract}

\begin{abstract}
Morus alba L. has been worldwide cultivated and commercially exploited plant with profound potential in environmental management, food and medicinal industries. Plant-associated microbial communities are playing an essential role in sustainable plant development. In the present study, the bacterial and fungal microorganism populations distributed on the white mulberry fruits harvested in the Czech Republic for the first time were characterized by metagenomics approach. A total of 62 bacterial and 37 fungal families were identified on white mulberry. Bacterial population was represented by the genera Tatumella, Leuconostoc, Frateuria and Pseudomonas, while fungal microorganisms - by Hanseniaspora, Cryptococcus, Cladosporium and Phoma. Both potentially beneficial, inducing resistance in the hosting plant, and pathogenic, responsible for disease development, microorganisms were detected. The information on the prevalence of bacterial and fungal microorganisms on the carposphere of $M$. alba is highly relevant for the development of strategies for environment-friendly plant cultivation, disease management and prevention.
\end{abstract}

Keywords: metagenomic analysis, Moraceae, fungal microbiota, bacterial microbiota.

Online supplementary material: Supporting information for this paper is available as online supplementary material at https://doi.org/10.3846/jeelm.2020.13735

\section{Introduction}

Mulberry trees (Morus L.) have been widely cultivated in temperate and subtropical regions of Africa, America, Asia and Europe; their planting steadily increases every year due to realized economic and ecological benefits $(\mathrm{Ou}$ et al., 2019; Xu et al., 2019). Mulberry (Morus spp.) has been commercially exploited as the host of the silkworm (Bombyx mori). Mulberry leaves and fruits contain a variety of nutrient and nutraceutical substances. Fruits have been recognized as a kind of natural nutrition and functional food; they are usually eaten fresh or made into jam, juice and wine (Łochyńska, 2015). Due to the presence of anthocyanins, carotenoids and flavonoids, mulberry fruits possess potential pharmacological properties including antibacterial, antidiabetic, antiobesity and antioxidative effects (Mahboubi, 2019; Rodrigues et al., 2019; Zhang et al., 2018). Rapid development of industry, transportation, introduction of anthropogenic toxic pollutants to the atmosphere, soil and groundwater possess serious threats on the remediation capacity of the environment (da Silva et al., 2017; Jiang et al., 2017; Khoshdel \& Vaziri, 2016). Mulberry's developed root system has the potential to absorb heavy metals from contaminated soil and water, and to degrade organic compounds. Mulberry leaves absorb atmospheric pollutants. Planting of mulberry can effectively improve soil permeability and water balance, modify soil chemical and physical properties (Jiang et al., 2017).

Morus alba, rubra and nigra are the best-known mulberry species. The white mulberry (Morus alba L.) is very

*Corresponding author. E-mail: elena.serviene@vgtu.lt 
populated species, however almost forgotten in Europe. The potential of Morus L. plants in agriculture, environmental protection, industry and human health is rather huge (Łochyńska, 2015; Ercisli \& Orhan, 2007). M. alba leaves can be used for tea making and in the silkworm diet for the commercial production of silk (Mahboubi, 2019). Very fast growth of white mulberry tree produces significant amount of plant biomass, which may be used as the renewable source of biofuel (Łochyńska, 2015; Chinnaswamy \& Harisparad, 1995). Due to natural dyeing properties, it is applicable in furniture industry (Łochyńska, 2015). The food industry increasingly uses white mulberry in food production to provide valuable bioactive substances (Łochyńska, 2015). The main active constituents of $M$. alba include flavonoids, alkaloids, stilbenes, and polysaccharides, providing health benefits through anti-inflammatory and immunomodulatory effects (Zhang et al., 2018). Fruits, roots, and leaves of $M$. alba are used also for the treatment of dizziness, insomnia, and premature aging (Rodrigues et al., 2019). The resistance to disease and pests, relatively low soil requirements as well as attractive bioremediation properties substantiate great potential of $M$. alba for landscaping and ecological environment management (Jiang et al., 2017).

Economic value of the mulberry fruit is constantly increasing, so is the need for plant cultivation and disease management to produce suitable for consumption berries. Among multiple biotic and abiotic factors affecting plant development, plant-associated microbial communities are playing one of the primary roles. It must be mentioned that very few works concentrated on the characterization of mulberryassociated microbial assemblages are published so far. Some studies are focused on the diversity of endophytic bacteria on white mulberry cultivars by revealing seasonal variation and emphasizing antimicrobial and plant growth-promoting activities of bacteria (Ou et al., 2019; Xu et al., 2019). Only two studies are intended for characterization of soil fungal communities of different white mulberry genotypes and analysis of relationship with fruit sclerotiniosis (Zhang et al., 2019; Yu et al., 2016). To the best of our knowledge, the white mulberry carposphere-associated microbial populations remain undescribed in the scientific literature. The aim of the present study was to characterize the bacterial and fungal microorganism communities found on the M. alba fruit surface by applying metabarcoding and Next Generation Sequencing (NGS) technology.

\section{Materials and methods}

\subsection{White mulberry sample preparation}

Morus alba $L$. fruits were aseptically sampled from 30-40 years-old planted trees growing in Ostrava city park (the Czech Republic, GPS coordinates: $49^{\circ} 50^{\prime} 1^{\prime \prime} \mathrm{N}, 18^{\circ} 17^{\prime} 40^{\prime \prime} \mathrm{E}$ ) in July, 2016. The fruits (at medium ripeness stage, without blemish) were randomly collected from reachable branches of the five white mulberry trees growing in distance of more than 30 meters. M. alba fruits were combined into sterile plastic bags and within 2 hours after harvesting were transported on ice to the Ostrava University for further processing. Gathered fruits ( 300 g) were washed with aseptic $0.05 \mathrm{M}$ phosphate buffer, $\mathrm{pH} 6.8(500 \mathrm{~mL})$ for $30 \mathrm{~min}$ at room temperature. Plant debris was removed by filtration through $420 \mu \mathrm{m}$ filters. Samples were centrifuged at $12,000 \times \mathrm{g}$ for $20 \mathrm{~min}$. The collected pellet was transported on ice to Lithuania and kept in $-20^{\circ} \mathrm{C}$ freezer until DNA extraction and amplification of marker genes (Department of Chemistry and Bioengineering, Vilnius Gediminas Technical University).

\subsection{Extraction of DNA and sequencing}

The DNA was extracted from $40 \mathrm{mg}$ of collected pellet using a Genomic DNA purification kit (Thermo Fisher Scientific Baltics, Vilnius, Lithuania). The isolated DNA was quality checked and quantified by Nanodrop 2000 spectrophotometer (Thermo Fisher Scientific). V3-V4 variable regions of the bacterial $16 \mathrm{~S}$ rRNA gene were amplified by the primer set S-D-Bact-0341-b-S-17 (5'-CCTACGGGNGGCWGCAG-3') and S-D-Bact-0785-a-A-21 (5'-GACTACHVGGGTATCTAATCC-3') and used to classify bacteria. The ITS2 region of ribosomal DNA specific primers ITS3-KYO2 (5'-GATGAAGAACGYAGYRAA-3') and ITS4 (5'-TCCTCCGCTTATTGATATGC-3') were applied for fungal microorganism identification. Amplicon library preparation and sequencing was performed by Macrogen Inc. (Seoul, Korea). The libraries were sequenced using Illumina MiSeq V3 as paired-end $2 \times 300$ bp reads. Raw sequencing data was submitted to the NCBI Short Read Archive (SRA) database (Accession Number PRJNA612435).

\subsection{Sequence analysis}

Bioinformatics analysis was conducted using FLASH v1.2.11 (Magoč \& Salzberg, 2011) to filter sequences with a minimum $\mathrm{Q}$ score of 25 and merge paired-reads. OTUs were picked by the greedy heuristic clustering algorithm, CD-HIT-OTU v4.5.5 (Li et al., 2012). Alpha diversity was calculated (including Chao1, Shannon, Good coverage) and relative abundance summaries were conducted using QIIME 1.8 (Caporaso et al., 2010). UNITE (Kõljalg et al., 2013) and Ribosomal Database Project (RDP) (Cole et al., 2014) were used as the reference databases for the taxonomy assignments of most abundant sequences. Non-bacterial, non-fungal sequences and singletons were filtered out and taxonomic relative abundance at all classification levels was calculated. The taxonomic results were visualized in Krona (Ondov et al., 2011).

\section{Results}

\subsection{Bacterial and fungal diversity of $M$. alba fruits}

The Illumina MiSeq sequencing generated 516,658 and 554,058 paired-end reads from ITS2 and V3-V4 target regions respectively. Following quality filtering and checking of chimera sequences, 302,705 (for ITS2) and 169,313 (for V3-V4) reads were obtained. 97\% threshold of sequence similarity was used for clustering into operational 
Table 1. Summary of ITS2 and 16S rRNA gene amplicon sequence analysis and microbial community diversity parameters

\begin{tabular}{|l|c|c|c|c|c|c|c|}
\hline & Target region & $\begin{array}{c}\text { Reads } \\
\text { obtained }\end{array}$ & $\begin{array}{c}\text { High quality } \\
\text { reads }\end{array}$ & OTU & Chao1 & $\begin{array}{c}\text { Goods } \\
\text { coverage }\end{array}$ & $\begin{array}{c}\text { Shannon } \\
\text { diversity }\end{array}$ \\
\hline \multirow{2}{*}{ Morus alba } & ITS2 & 516,658 & 302,705 & 206 & 215 & 0.99996 & 2.95 \\
\cline { 2 - 9 } & V3-V4 & 554,058 & 169,313 & 365 & 370 & 0.99997 & 4.56 \\
\hline
\end{tabular}

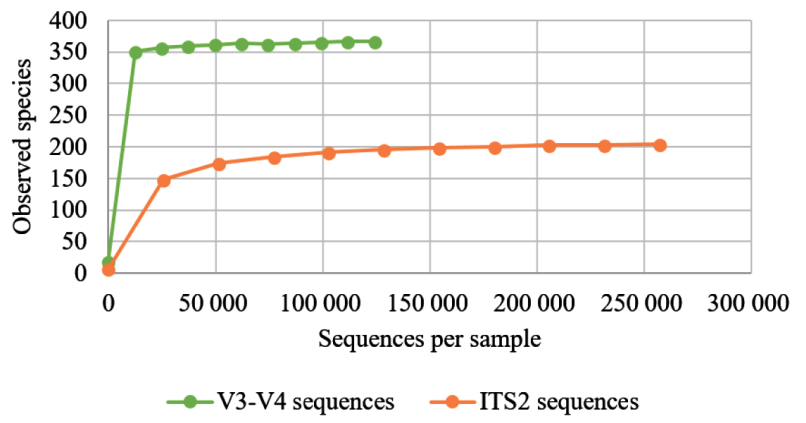

Figure 1. Rarefaction curves describing M. alba fruit-associated species richness at a genetic distance of $3 \%$ for each sample.

ITS2 sequences from the analysis of eukaryotic microbial community and V3-V4 region sequences from the analysis of prokaryotic microbial community

taxonomic units (OTUs) (Table 1). 365 bacterial and 206 fungal OTUs were represented by identified sequences. Rarefaction curves (Figure 1) and calculated Goods coverage confirmed that the majority of the bacterial (coverage: $99.9 \%$ ) and the fungal OTUs (coverage: $99.9 \%$ ) were recovered. In agreement with obtained OTU data, the Chaol and Shannon indexes demonstrated that white mulberry had higher bacterial community diversity than fungal microorganisms.

\subsection{Taxonomic composition of white mulberry bacterial microbiota}

The obtained sequences were classified into 14 phyla, 22 classes, 32 orders, 62 families and 87 genera (Table S1). The dominating bacterial phyla were Proteobacteria (61.72\%), Firmicutes (24.88\%), Bacteroidetes (4.38\%), and Actinobacteria $(2.36 \%)$, collectively accounting for more than $93 \%$ of the total bacterial population. Prokaryotic microorganisms essentially belonged to Gammaproteobacteria (50.92\%) and Bacilli (24.79\%) at the class level. The first class was represented by bacteria from Enterobacteriales, Xanthomonadales and Pseudomonadales orders, while the second - by Lactobacillales. Among 62 bacterial families identified, Enterobacteriaceae (28.43\%), Leuconostocaceae (23.43\%), Xanthomonadaceae (12.7\%) and Pseudomonadaceae (7.72\%) were the most abundant, represented mainly by the genera Tatumella (19.5\%), Leuconostoc (21.58\%), Frateuria (12.45\%) and Pseudomonas (7.72\%) (Table S1, Figure 2). The analysis of unique bacterial OTUs allowed to identify at the species level 10 prokaryotic microorganisms, with the highest abundance Frateuria aurantia (12.6\%) and Gluconobacter kanchanaburiensis (4.37\%), while other species were assigned to uncultured bacteria (Table 2, Table S1).
Table 2. List and relative abundance of bacterial and fungal microorganisms identified at species level

\begin{tabular}{|c|c|}
\hline \multicolumn{2}{|c|}{ Bacterial relative abundance, $\%$} \\
\hline Frateuria aurantia DSM 6220 & 12.60 \\
\hline Gluconobacter kanchanaburiensis & 4.37 \\
\hline Paenibacillus hordei & 0.78 \\
\hline Nodularia spumigena & 0.12 \\
\hline Lonsdalea quercina subsp. britannica & 0.12 \\
\hline Lysinibacillus sphaericus & 0.04 \\
\hline Pseudomonas geniculata & 0.04 \\
\hline Rhizobium leguminosarum bv. viciae & 0.02 \\
\hline Myxococcus virescens & 0.02 \\
\hline Vagococcus teuberi & 0.01 \\
\hline \multicolumn{2}{|c|}{ Fungal microorganisms relative abundance, $\%$} \\
\hline Hanseniaspora uvarum & 34.04 \\
\hline Cryptococcus laurentii & 8.18 \\
\hline Cryptococcus magnus & 2.17 \\
\hline Candida railenensis & 0.34 \\
\hline Torulaspora delbrueckii & 0.24 \\
\hline Auriculibuller fuscus & 0.21 \\
\hline Sporobolomyces roseus & 0.20 \\
\hline Bulleromyces albus & 0.11 \\
\hline Wickerhamomyces anomalus & 0.05 \\
\hline Sporobolomyces salicinus & 0.04 \\
\hline Sporobolomyces gracilis & 0.04 \\
\hline Udeniomyces pannonicus & 0.04 \\
\hline Verticillium dahliae & 0.04 \\
\hline Erythrobasidium hasegawianum & 0.04 \\
\hline Dioszegia catarinonii & 0.04 \\
\hline Monographella nivalis & 0.03 \\
\hline Sarocladium strictum & 0.03 \\
\hline Cryptococcus uzbekistanensis & 0.03 \\
\hline Cystofilobasidium lari_marini & 0.02 \\
\hline Exophiala psychrophila & 0.02 \\
\hline Fusarium culmorum & 0.02 \\
\hline Sporobolomyces coprosmae & 0.01 \\
\hline Mrakiella aquatica & 0.01 \\
\hline Dioszegia aurantiaca & 0.01 \\
\hline Knufia cryptophialidica & 0.01 \\
\hline Saccharomycopsis crataegensis & 0.01 \\
\hline Colletotrichum acutatum & 0.01 \\
\hline Septoria lepidii & 0.01 \\
\hline Kondoa malvinella & 0.01 \\
\hline Botryotinia fuckeliana & 0.01 \\
\hline Chaetomium murorum & 0.01 \\
\hline
\end{tabular}




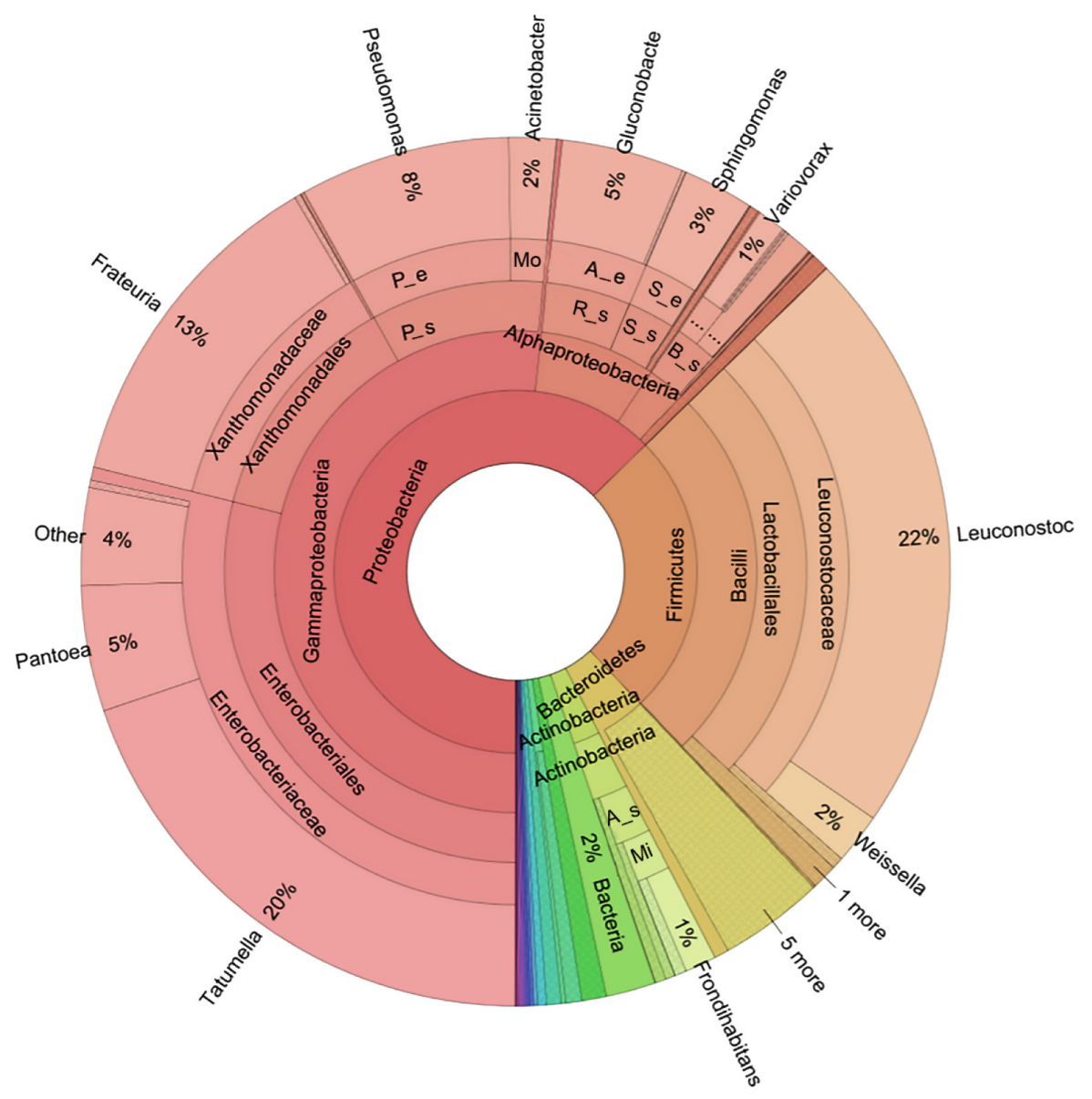

Figure 2. Prokaryotic microbial community distribution on M. alba carposphere. A_e - Acetobacteriaceae;

A_s - Actinomycetales; B_s - Bulkholderiales; R_s - Rhodospirillales; S_e - Sphingomonadaceae; S_s - Sphingomonadales; P_e - Pseodomonadaceae; P_s - Pseudomonadales; Mo - Moraxellaceae; Mi - Microbacteriaceae. Minor OTUs were not labeled. Pie-charts were constructed using KRONA (Ondov et al., 2011)

\subsection{Composition of white mulberry carposphere fungal microbiota}

In total, 65 genera of fungi from 4 classified phyla, 13 classified classes, 26 classified orders, 37 classified families were detected (Table S2). The fungal microbiota was mostly dominated by Ascomycota phylum (76.42\%), followed by Basidiomycota (21.52\%) and unidentified microorganisms (1.99\%). Dothideomycetes $(40.32 \%)$, Saccharomycetes $(34.83 \%)$ and Tremellomycetes $(20.79 \%)$ have been identified to be the major classes associated with white mulberry fruits. At the family level, the eukaryotic microorganisms were represented by Saccharomycodaceae (34.04\%) and Dothioraceae $(31.08 \%)$. Fungal microorganisms belonging to Dothioraceae family were assigned as uncultured $\mathrm{Au}$ reobasidium at the species level (31.08\%) (Table S2). The dominant genus distributed on mulberry fruits was Hanseniaspora (34.04\%), followed by Cryptococcus (16.84\%), Cladosporium (4.73\%), and Phoma (4.06\%) (Table S2; Figure 3). Thirty one fungal microorganism species were identified with dominating Hanseniaspora uvarum (34.04\%), Cryptococcus laurentii (8.2\%) and Cryptococcus magnus (2.2\%) (Table 2).

\section{Discussion}

So far, a few studies were focused on the characterization of bacterial community distributed on different Morus L. cultivars using culture-dependent (Xu et al., 2019) and metagenomics (Ou et al., 2019) approaches. It was demonstrated that the endophytic Morus L. microorganism assemblies are specific for the host plant and the climatic conditions (Ou et al., 2019). Several aspects aggravate comparative analysis of our data with previous Morus L. microbiome studies: different plant site were chosen (in our study - fruits, in in mentioned above studies - stems), the lack of information on exact mulberry species of tested cultivars, and microorganisms analyzed (ours - epiphytic, in mentioned above studies - endophytic bacteria). Nevertheless, analysis of taxonomic composition of prokaryotic microorganisms revealed that Actinobacteria, Firmicutes, and Proteobacteria were the three most abundant bacterial phyla on different Morus L. cultivars, mainly represented by Pantoea, Pseudomonas, and Methylobacterium genera (Ou et al., 2019; Xu et al., 2019). In our study, about 90\% of $M$. alba fruits were also covered by microorganisms belonging to these phyla but represented by different genera. At genus level, Leuconostoc was the most prevalent taxa 


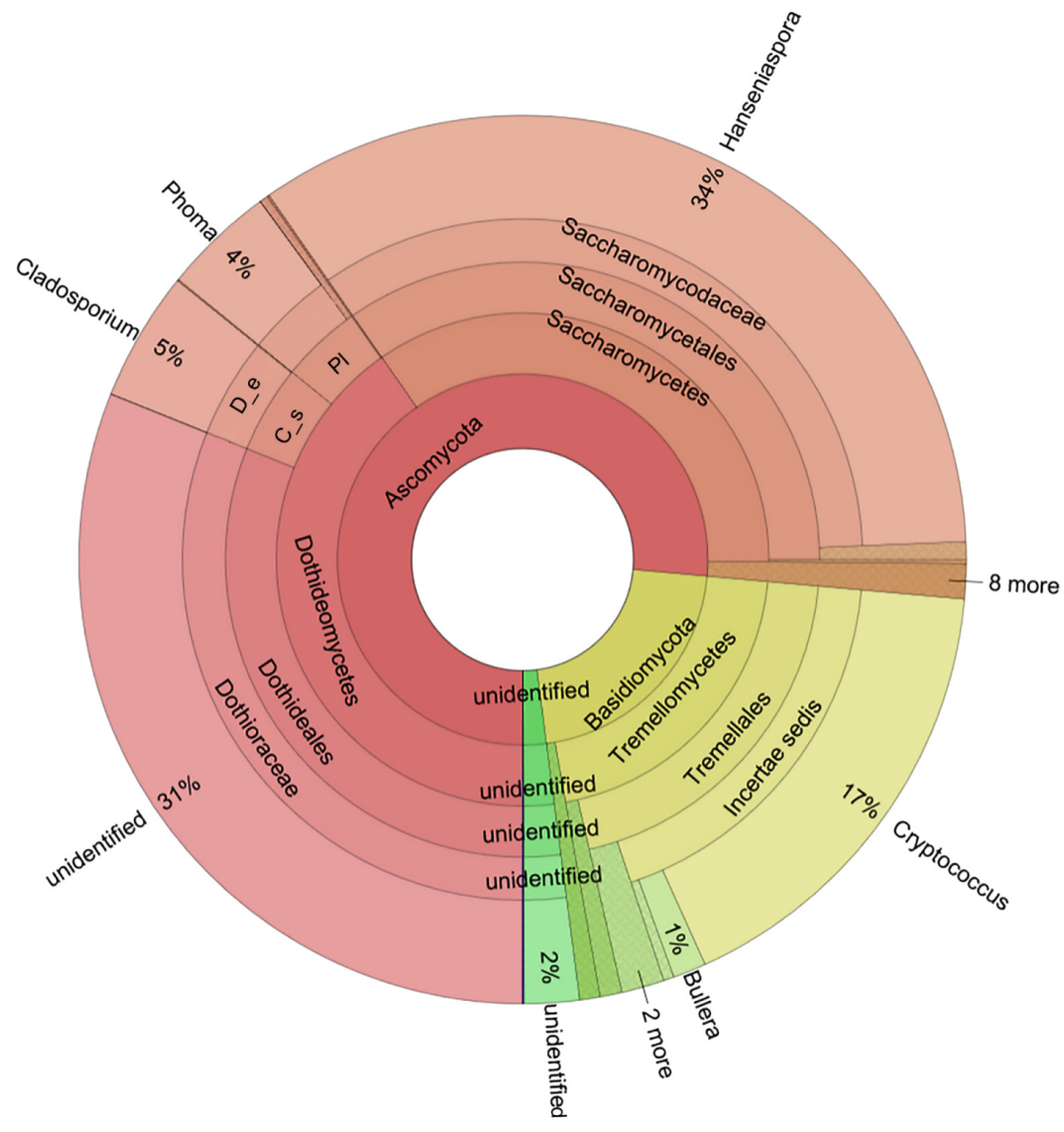

Figure 3. The taxonomic distribution of fungal microorganisms on M. alba carposphere. C_s - Capnodiales; D_e - Davidiellaceae; $\mathrm{Pl}$ - Pleosporales. Minor OTUs were not labeled. Pie-charts were constructed using KRONA (Ondov et al., 2011)

on white mulberry fruits. Leuconostoc spp. are non-pathogenic bacteria frequently found on plants, advantageous in most foods because of their flavor development and preservation abilities, capacity to improve the nutritional and organoleptic quality, possessing beneficial effects as potential probiotics (Shin \& Han, 2015; Holland \& Liu, 2011). Some Leuconostoc species are also capable of causing uncommon human infections or wine ropiness, nevertheless the genus is generally recognized as safe (Holland \& Liu, 2011). In our study, Tatumella and Frateuria were detected among dominating bacterial genera on M. alba fruits. Some representatives of Tatumella genus are foodborne opportunistic pathogens isolated from various food sources, pineapples and clinical specimens, able to cause numerous infections (Mardaneh et al., 2014). Frateuria bacteria, represented in our study by Frateuria aurantia, were previously documented as capable to improve the plant growth and control phytopathogens (Lidor et al., 2019). Bacteria from Pseudomonas and Pantoea genera, observed in high content on white mulberry plants, are reported as plant-associated pathogenic microorganisms (Coutinho \& Venter, 2009; Ligon et al., 2000). Nevertheless, both genera contain species possessing antimicrobial features (Trotel-Aziz et al., 2008; Ligon et al., 2000).
Among those identified at species level in low frequency, bacteria with known plant growth promoting and biocontrol potential (Pseudomonas geniculate, Lysinibacillus sphaericus, Myxococcus virescens, Rhizobium leguminosarum bv. viciae) were observed.

So far, only two studies using molecular techniques have described the fungal communities related to a $M$. alba tree, in the investigation conducted on soil samples (Zhang et al., 2019; Yu et al., 2016). It was demonstrated that representatives of six phyla were observed with three dominant phyla (Ascomycota, Mucoromycota and Basidiomycota) (Zhang et al., 2019), while fruits were mainly covered by representatives of two phyla as revealed in our study. Based on mulberry rhizosphere-associated fungal community analysis, it has been shown that plant genotype has a significant influence on the abundance and composition of soil microbial population (Yu et al., 2016). In addition, the differences in the soil microbial assemblages may affect the plant resistance to mulberry fruit sclerotiniosis (Yu et al., 2016). As observed in our study, Hanseniaspora was the most prevalent mulberry fruit-associated taxa at the genus level, represented by Hanseniaspora uvarum species. Hanseniaspora spp. possess low fermentative activity and have been frequently 
Table 3. Most abundant bacterial and fungal microorganisms on the Morus alba carposphere in comparison to those on Malus pumila and Ribes nigrum. Taxonomy analyzed at genus level. $\mathrm{Cz}$-fruits collected in Czech Republic, LT - in Lithuania. Data on distribution of apple and blackcurrant microbiota obtained from Vepštaitė-Monstavičè et al. (2018)

\begin{tabular}{|c|c|c|c|c|c|}
\hline \multirow{2}{*}{ Genus } & M. alba_CZ & M. pumila_LT & M. pumila_CZ & R. nigrum_LT & R. nigrum_CZ \\
\hline & \multicolumn{5}{|c|}{ Bacteria relative abundance, $\%$} \\
\hline Leuconostoc & 21.83 & 0.00 & 0.01 & 0.00 & 0.00 \\
\hline Tatumella & 19.73 & 0.00 & 0.01 & 0.00 & 18.91 \\
\hline Frateuria & 12.60 & 0.00 & 0.00 & 0.00 & 0.00 \\
\hline Pseudomonas & 7.81 & 32.57 & 41.26 & 2.80 & 7.78 \\
\hline Pantoea & 4.66 & 48.70 & 34.16 & 0.38 & 1.02 \\
\hline Gluconobacter & 4.53 & 0.12 & 0.12 & 0.00 & 5.49 \\
\hline Sphingomonas & 2.63 & 0.57 & 2.21 & 1.17 & 7.41 \\
\hline Weissella & 1.88 & 0.06 & 0.00 & 0.00 & 0.00 \\
\hline Acinetobacter & 1.76 & 0.00 & 0.00 & 4.61 & 0.00 \\
\hline Frondihabitans & 1.17 & 1.60 & 0.96 & 0.26 & 1.79 \\
\hline Hymenobacter & 1.10 & 0.27 & 0.80 & 0.49 & 7.00 \\
\hline \multirow[t]{2}{*}{ Variovorax } & 1.05 & 0.04 & 0.00 & 0.82 & 2.32 \\
\hline & \multicolumn{5}{|c|}{ Fungal microorganisms relative abundance, $\%$} \\
\hline Hanseniaspora & 34.04 & 3.26 & 17.62 & 0.00 & 48.53 \\
\hline Cryptococcus & 16.86 & 5.68 & 3.48 & 15.22 & 0.88 \\
\hline Cladosporium & 4.73 & 4.19 & 1.76 & 45.40 & 5.20 \\
\hline Phoma & 4.06 & 0.44 & 0.66 & 3.99 & 1.64 \\
\hline Bullera & 1.21 & 0.06 & 0.05 & 0.14 & 0.00 \\
\hline
\end{tabular}

discovered on the surface of different fruits, e.g. apples, blackcurrants, grapes, strawberries and etc. (Lukša et al., 2018; Vepštaitė-Monstavičè et al., 2018; Graça et al., 2015). It is well-recognized that fungal microorganisms from this genus could be useful to hosting plant by executing antagonistic activity on the development of fruit spoilage-causing mold (Tilocca et al., 2020; Liu et al., 2010). Among other dominating fungal genera, our study on mulberry fruits detected Cryptococcus, Cladosporium, and Phoma. Ubiquitous fungi Cryptococcus and Cladosporium are typical members of the yeast population have been often detected on the surface of different plants (VepštaiteMonstavičè et al., 2018; Vadkertiová et al., 2012). Some representatives of these genenera enclose species producing antifungal agents against many pathogens (Freimoser et al., 2019; Hashem et al., 2014; Wang et al., 2013), and have been established as biocontrol agents for the management of the postharvest diseases (Liu et al., 2013). On the other hand, certain species can cause plant, human and animal diseases (Sandoval-Denis et al., 2016; BernalMartinez et al., 2010). Therefore, the potentially beneficial or pathogenic features of Cryptococcus laurentii and Cryptococcus magnus fungal microorganisms, identified in our study, could be determined only by culture isolation and further analysis. Fungal microorganisms belonging to the genus Phoma are known to be plant pathogens, characterized by parasitic relationships with their host (Aveskamp et al., 2008). Phoma spp. have been shown to contaminate seeds, fruits and vegetables (Bennett et al., 2018; Lukša et al., 2018; Vepštaitè-Monstavičè et al., 2018; Oliveira et al., 2017; Termorshuizen, 2007), produce cytotoxic metabolites causing infections for humans and animals (Bennett et al., 2018). Among identified at species level in low frequency, potentially beneficial (Torulaspora delbrueckii, Wickerhamomyces anomalus, Candida railenensis, etc) as well as pathogenic fungi (Auriculibuller fuscus, Bulleromyces albus, Sporobolomyces roseus, Sp. salicinus, Sp. gracilis, etc) were observed.

The abundance and distribution of prokaryotic and eukaryotic microorganisms on fruits are dependent on the plant origin and ripening stage, geographic location and climatic conditions, application of agrochemicals as well as other biotic and abiotic factors (Vepštaitè-Monstavičè et al., 2018; Pinto et al., 2015). Considering the biogeographic effect, we compared the $M$. alba-associated microbial communities with ones identified previously on Malus pumila Mill. and Ribes nigrum L. collected in Czech Republic, Ostrava region and Lithuania (VepstaiteMonstavičè et al., 2018) (Table 3). All tested fruits were sampled in the same season on July-August, 2016. The higher amount of bacteria belonging to Tatumella, Gluconobacter and Sphingomonas genera and fungal microorganisms from Hanseniaspora genus were detected on the surface of fruits sampled in Czech Republic, as compared to Lithuanian samples. These results indicate the importance of climatic conditions and geographical distribution 
on the prevalence of microorganisms. On the other hand, detection of bacteria from Leuconostoc and Frateuria genera exceptionally on $M$. alba revealed importance of the plant origin. Higher abundance of Pseudomonas spp. and Pantoea spp. on M. pumila comparing to M. alba and $R$. nigrum from both localities as well as dominance of Phoma spp. on M. alba and R. nigrum further highlights the plant-conditioned distribution. The differences between the microbial communities inhabiting various plants are determined by various hosting plant features, including production of volatile organic compounds as well as interactions of microorganisms with the plant and other microbial inhabitants (Deveau et al., 2018; Lindow \& Brandl, 2003). In the natural environment, different factors act cumulatively, therefore differentiation of the major and specific impacts driving the divergence of bacterial and fungal microorganism assemblages is rather complicated.

In conclusion, the results of this study demonstrated that $M$. alba carposphere possesses high bacterial and fungal microorganism variety. Among eukaryotic and prokaryotic microbiota, both potentially beneficial and pathogenic microorganisms were identified. The obtained information on the structure of white mulberry-associated fungal and bacterial assemblages, spreading of potentially beneficial and phytopathogenic microorganisms is important to develop effective plant disease control strategy. Due to clear potential of white mulberry berries in food industry, the metagenomics data appear to be significant for the evaluation of the influence of microbiota in general, and specific microorganisms in particular on food quality and human wellbeing.

\section{Acknowledgements}

We would like to thank Dr. V. Yurchenko and Dr. T. Yurchenko for helping with the sample collection.

\section{Conflict of interest}

The authors declare no conflict of interest.

\section{Author contributions}

Conceptualization, E. S.; collection of plant material, E. S.; metagenomic analysis of microorganisms, J. L., E. S.; bioinformatics analysis, J. L.; data interpretation, E. S., J. L.; writing - original draft, E. S., J. L.

\section{References}

Aveskamp, M. M., De Gruyter, J., \& Crous, P. W. (2008). Biology and recent developments in the systematics of Phoma, a complex genus of major quarantine significance. Fungal Diversity, 31, 1-18.

Bennett, A., Ponder, M., \& Garcia-Diaz, J. (2018). Phoma infections: classification, potential food sources, and their clinical impact. Microorganisms, 6(3), 58.

https://doi.org/10.3390/microorganisms6030058
Bernal-Martinez, L., Gomez-Lopez, A., Castelli, M. V., MesaArango, A. C., Zaragoza, O., Rodriguez-Tudela, J. L., \& Cuenca-Estrella, M. (2010). Susceptibility profile of clinical isolates of non-Cryptococcus neoformans/non-Cryptococcus gattii Cryptococcus species and literature review. Medical Mycology, 48(1), 90-96. https://doi.org/10.3109/13693780902756073

Caporaso, J. G., Kuczynski, J., Stombaugh, J., Bittinger, K., Bushman, F. D., Costello, E. K., Fierer, N., Peña, A. G., Goodrich, J. K., Gordon, J. I., Huttley, G. A., Kelley, S. T., Knights, D., Koenig, J. E., Ley, R. E., Lozupone, C. A., McDonald, D., Muegge, B. D., Pirrung, M., Reeder, J., Sevinsky, J. R., Turnbaugh, P. J., Walters, W. A., Widmann, J., Yatsunenko, T., Zaneveld, J., \& Knight, R. (2010). QIIME allows analysis of high-throughput community sequencing data. Nature Methods, 7(5), 335-336.

https://doi.org/10.1038/nmeth.f.303

Chinnaswamy, K. P., \& Harisprasad, K. B. (1995). Energy potentiality of mulberry. Indian Silk, 34(4), 15-18.

Cole, J. R., Wang, Q., Fish, J. A., Chai, B., McGarrell, D. M., Sun, Y., Brown, C. T., Porras-Alfaro, A., Kuske, C. R., \& Tiedje, J. M. (2014). Ribosomal Database Project: Data and tools for high throughput rRNA analysis. Nucleic Acids Research, 42(D1), D633-D642. https://doi.org/10.1093/nar/gkt1244

Coutinho, T. A., \& Venter, S. N. (2009). Pantoea ananatis: An unconventional plant pathogen. Molecular Plant Pathology, 10(3), 325-335. https://doi.org/10.1111/j.1364-3703.2009.00542.x

da Silva, A. M., Urban, R. C., Manfre, L. A., Brossard, M., \& Moreira, M. Z. (2017). Soil quality attributes related to urbanization in Brazilian watershed. Journal of Environmental Engineering and Landscape Management, 25(4), 317-328. https://doi.org/10.3846/16486897.2017.1296451

Deveau, A., Bonito, G., Uehling, J., Paoletti, M., Becker, M., Bindschedler, S., Hacquard, S., Herve, V., Labbe, J., Lastovetsky, O., Mieszkin, S., Millet, L. J., Vanja, B., Junier, P., Bonfante, P., Krom, B., Olsson, S., van Elsas, J. D., \& Wick, L. (2018). Bacterial - fungal interactions: Ecology, mechanisms and challenges. FEMS Microbiology Reviews, 42(3), 335-352. https://doi.org/10.1093/femsre/fuy008

Ercisli, S., \& Orhan, E. (2007). Chemical composition of white (Morus alba), red (Morus rubra) and black (Morus nigra) mulberry fruits. Food Chemistry, 103(4), 1380-1384.

https://doi.org/10.1016/j.foodchem.2006.10.054

Freimoser, F. M., Rueda-Mejia, M. P., Tilocca, B., \& Migheli, Q. (2019). Biocontrol yeasts: Mechanisms and applications. World Journal of Microbiology and Biotechnology, 35, 154. https://doi.org/10.1007/s11274-019-2728-4

Graça, A., Santo, D., Esteves, E., Nunes, C., Abadias, M., \& Quintas, C. (2015). Evaluation of microbial quality and yeast diversity in fresh-cut apple. Food Microbiology, 51, 179-185. https://doi.org/10.1016/j.fm.2015.06.003

Hashem, M., Alamri, S. A., Hesham, A. E. L., Al-Qahtani, F. M. H., \& Kilany, M. (2014). Biocontrol of apple blue mould by new yeast strains: Cryptococcus albidus KKUY0017 and Wickerhamomyces anomalus KKUY0051 and their mode of action. Biocontrol Science and Technology, 24(10), 11371152. https://doi.org/10.1080/09583157.2014.926857

Holland, R., \& Liu, S.-Q. (2011). Lactic Acid Bacteria | Leuconostoc spp. In Encyclopedia of dairy sciences (pp. 138-142). Elsevier. https://doi.org/10.1016/B978-0-12-374407-4.00267-3

Jiang, Y., Huang, R., Yan, X., Jia, C., Jiang, S., \& Long, T. (2017). Mulberry for environmental protection. Pakistan Journal of Botany, 49(2), 781-788. 
Kõljalg, U., Nilsson, R. H., Abarenkov, K., Tedersoo, L., Taylor, A. F. S., Bahram, M., Bates, S. T., Bruns, T. D., Bengtsson-Palme, J., Callaghan, T. M., Douglas, B., Drenkhan, T., Eberhardt, U., Dueñas, M., Grebenc, T., Griffith, G. W., Hartmann, M., Kirk, P. M., Kohout, P., Larsson, E., Lindahl, B. D., Lücking, R., Martín, M. P., Matheny, P. B., Nguyen, N. H., Niskanen, T., Oja, J., Peay, K. G., Peintner, U., Peterson, M., Põldmaa, K., Saag, L., Saar, I., Schüßler, A., Scott, J. A., Senés, C., Smith, M. E., Suija, A., Taylor, D. L., Telleria, M. T., Weiss, M., \& Larsson, K.-H. (2013). Towards a unified paradigm for sequence-based identification of fungi. Molecular Ecology, 22(21), 5271-5277. https://doi.org/10.1111/mec.12481

Khoshdel, A., \& Vaziri, B. M. (2016). Novel mathematical models for prediction of microbial growth kinetics and contaminant degradation in bioremediation process. Journal of Environmental Engineering and Landscape Management, 24(3), 157164. https://doi.org/10.3846/16486897.2016.1142446

Li, W., Fu, L., Niu, B., Wu, S., \& Wooley, J. (2012). Ultrafast clustering algorithms for metagenomic sequence analysis. Briefings in Bioinformatics, 13(6), 656-668. https://doi.org/10.1093/bib/bbs035

Lidor, O., Santos-Garcia, D., Mozes-Daube, N., Naor, V., Cohen, E., Iasur-Kruh, L., Bahar, O., \& Zchori-Fein, E. (2019). Frateuria defendens sp. nov., bacterium isolated from the yellows grapevine's disease vector Hyalesthes obsoletus. International Journal of Systematic and Evolutionary Microbiology, 69(5), 1281-1287. https://doi.org/10.1099/ijsem.0.003305

Ligon, J. M., Hill, D. S., Hammer, P. E., Torkewitz, N. R., Hofmann, D., Kempf, H.-J., \& Pee, K.-H. van. (2000). Natural products with antifungal activity from Pseudomonas biocontrol bacteria. Pest Management Science, 56(8), 688-695. https://doi.org/10.1002/1526-4998(200008)56:8<688::AIDPS186>3.0.CO;2-V

Lindow, S. E., \& Brandl, M. T. (2003). Microbiology of the phyllosphere. Applied and Environmental Microbiology, 69(4), 18751883. https://doi.org/10.1128/AEM.69.4.1875-1883.2003

Liu, H. M., Guo, J. H., Cheng, Y. J., Luo, L., Liu, P., Wang, B. Q., Deng, B. X., \& Long, C. A. (2010). Control of gray mold of grape by Hanseniaspora uvarum and its effects on postharvest quality parameters. Annals of Microbiology, 60(1), 31-35. https://doi.org/10.1007/s13213-010-0018-3

Liu, J., Sui, Y., Wisniewski, M., Droby, S., \& Liu, Y. (2013). Review: Utilization of antagonistic yeasts to manage postharvest fungal diseases of fruit. International Journal of Food Microbiology, 167(2), 153-160.

https://doi.org/10.1016/j.ijfoodmicro.2013.09.004

Łochyńska, M. (2015). Energy and nutritional properties of the white mulberry (Morus alba L.). Journal of Agricultural Science and Technology A, 5(9).

https://doi.org/10.17265/2161-6256/2015.09.001

Lukša, J., Vepštaitė-Monstavičè, I., Yurchenko, V., Serva, S., \& Serviene, E. (2018). High content analysis of sea buckthorn, black chokeberry, red and white currants microbiota - A pilot study. Food Research International, 111, 597-606.

https://doi.org/10.1016/j.foodres.2018.05.060

Magoč, T., \& Salzberg, S. L. (2011). FLASH: fast length adjustment of short reads to improve genome assemblies. Bioinformatics (Oxford, England), 27(21), 2957-2963.

https://doi.org/10.1093/bioinformatics/btr507

Mahboubi, M. (2019). Morus alba (mulberry), a natural potent compound in management of obesity. Pharmacological Research, 146, 104341.

https://doi.org/10.1016/j.phrs.2019.104341
Mardaneh, J., Soltan Dallal, M. M., Taheripoor, M., \& Rajabi, Z. (2014). Isolation, identification and antimicrobial susceptibility pattern of Tatumella ptyseos strains isolated from powdered infant formula milk consumed in neonatal intensive care unit: first report from Iran. Jundishapur Journal of Microbiology, 7(6), e10608. https://doi.org/10.5812/jjm.10608

Oliveira, R. C., Goncalves, S. S., Oliveira, M. S., Dilkin, P., Mallmann, C. A., Freitas, R. S., Bianchi, P., \& Correa, B. (2017). Natural occurrence of tenuazonic acid and Phoma sorghina in Brazilian sorghum grains at different maturity stages. Food Chemistry, 230, 491-496.

https://doi.org/10.1016/j.foodchem.2017.03.079

Ondov, B. D., Bergman, N. H., \& Phillippy, A. M. (2011). Interactive metagenomic visualization in a Web browser. $B M C$ Bioinformatics, 12(1), 385.

https://doi.org/10.1186/1471-2105-12-385

Ou, T., Xu, W., Wang, F., Strobel, G., Zhou, Z., Xiang, Z., Liu, J., \& Xie, J. (2019). A microbiome study reveals seasonal variation in endophytic bacteria among different mulberry cultivars. Computational and Structural Biotechnology Journal, 17, 1091-1100. https://doi.org/10.1016/j.csbj.2019.07.018

Pinto, C., Pinho, D., Cardoso, R., Custódio, V., Fernandes, J., Sousa, S., Pinheiro M., Egas, C., \& Gomes, A. C. (2015). Wine fermentation microbiome: A landscape from different Portuguese wine appellations. Frontiers in Microbiology, 6, 905. https://doi.org/10.3389/fmicb.2015.00905

Rodrigues, E. L., Marcelino, G., Silva, G. T., Figueiredo, P. S., Garcez, W. S., Corsino, J., Guimarães, R. de C. A., \& Freitas, K. de C. (2019). Nutraceutical and medicinal potential of the Morus species in metabolic dysfunctions. International Journal of Molecular Sciences, 20(2), 301. https://doi.org/10.3390/ijms20020301

Sandoval-Denis, M., Gené, J., Sutton, D. A., Wiederhold, N. P., Cano-Lira, J. F., \& Guarro, J. (2016). New species of Cladosporium associated with human and animal infections. Persoonia - Molecular Phylogeny and Evolution of Fungi, 36(1), 281-298. https://doi.org/10.3767/003158516X691951

Shin, S.-Y., \& Han, N. S. (2015). Leuconostoc spp. as starters and their beneficial roles in fermented foods. In M. T. Liong (Ed.), Beneficial Microorganisms in food and nutraceuticals. Microbiology monographs (Vol. 27, pp. 111-132). Springer, Cham. https://doi.org/10.1007/978-3-319-23177-8_5

Termorshuizen, A. J. (2007). Fungal and fungus-like pathogens of potato. In Potato biology and biotechnology (pp. 643-665). Elsevier. https://doi.org/10.1016/B978-044451018-1/50071-3

Tilocca, B., Cao, A., \& Migheli, Q. (2020). Scent of a Killer: Microbial volatilome and its role in the biological control of plant pathogens. Frontiers in Microbiology, 11, 1-13. https://doi.org/10.3389/fmicb.2020.00041

Trotel-Aziz, P., Couderchet, M., Biagianti, S., \& Aziz, A. (2008). Characterization of new bacterial biocontrol agents Acinetobacter, Bacillus, Pantoea and Pseudomonas spp. mediating grapevine resistance against Botrytis cinerea. Environmental and Experimental Botany, 64(1), 21-32.

https://doi.org/10.1016/j.envexpbot.2007.12.009

Vadkertiová, R., Molnárová, J., Vránová, D., \& Sláviková, E. (2012). Yeasts and yeast-like organisms associated with fruits and blossoms of different fruit trees. Canadian Journal of Microbiology, 58(12), 1344-1352. https://doi.org/10.1139/cjm-2012-0468

Vepštaitè-Monstavičè, I., Lukša, J., Stanevičienè, R., StrazdaitèŽieliene, Ž., Yurchenko, V., Serva, S., \& Servienè, E. (2018). 
Distribution of apple and blackcurrant microbiota in Lithuania and the Czech Republic. Microbiological Research, 206, 1-8. https://doi.org/10.1016/j.micres.2017.09.004

Wang, X., Radwan, M. M., Taráwneh, A. H., Gao, J., Wedge, D. E., Rosa, L. H., Cutler, H. G., \& Cutler, S. J. (2013). Antifungal activity against plant pathogens of metabolites from the endophytic fungus cladosporium cladosporioides. Journal of Agricultural and Food Chemistry, 61(19), 4551-4555. https://doi.org/10.1021/jf400212y

Xu, W., Wang, F., Zhang, M., Ou, T., Wang, R., Strobel, G., Xiang, Z., Zhou, Z., \& Xie, J. (2019). Diversity of cultivable endophytic bacteria in mulberry and their potential for antimicrobial and plant growth-promoting activities. Microbiological Research, 229, 126328.

https://doi.org/10.1016/j.micres.2019.126328

Yu, C., Hu, X., Deng, W., Li, Y., Han, G., \& Ye, C. (2016). Soil fungal community comparison of different mulberry genotypes and the relationship with mulberry fruit sclerotiniosis. Scientific Reports, 6(1), 28365.

https://doi.org/10.1038/srep28365

Zhang, H., Ma, Z., Luo, X., \& Li, X. (2018). Effects of mulberry fruit (Morus alba L.) consumption on health outcomes: A mini-review. Antioxidants, 7(5), 69.

https://doi.org/10.3390/antiox7050069

Zhang, M. M., Wang, N., Zhang, J., Hu, Y., Cai, D., Guo, J., Wu, D., \& Sun, G. (2019). Soil physicochemical properties and the rhizosphere soil fungal community in a mulberry (Morus alba L.)/Alfalfa (Medicago sativa L.) intercropping system. Forests, 10(2), 167. https://doi.org/10.3390/f10020167 